\title{
Clinical Use of the Antiseptic Polihexanide for Genital Tract Infections
}

\author{
I. Koban ${ }^{a}$ C.P. Bender ${ }^{b}$ O. Assadian ${ }^{d}$ A. Kramer ${ }^{b}$ \\ N.-O. Hübner ${ }^{b, c}$ International Society of Chemotherapy Working Group \\ Antiseptics; Working Section for Clinical Antiseptic of the German Society for \\ Hospital Hygiene
}

a Unit of Periodontology, Department of Restorative Dentistry, Periodontology and Endodontology, University Medicine Greifswald, and ${ }^{b}$ Institute for Hygiene and Environmental Medicine, University Medicine Greifswald, Greifswald, and ${ }^{\mathrm{C}}$ Robert Koch Institute, Berlin, Germany; ${ }^{\mathrm{d} C l i n i c a l}$ Institute for Hospital Hygiene, Medical University of Vienna, Vienna, Austria

\section{Key Words}

Polihexanide Polyhexamethylene biguanide $\cdot$ Genital tract infection - Bacterial vaginosis $\cdot$ Human papilloma virus · Antisepsis · Antiseptic

\begin{abstract}
Background: In clinical practice, treatment of genital tract infections is based on administration of either antibiotics or antiseptics. While antibiotics may be applied systemically or topically, antiseptics may be applied only topically. In case of bacterial vaginosis (BV), antibiotic therapy may often be limited and side effects due to systemic administration may develop. Polihexanide (PHMB) is a promising option for the topical treatment of genital tract infections, in particular BV and vaginitis. Method: A systematic search for publications on the use of PHMB for the treatment of genital infections in two electronic databases was performed. Titles, abstracts and citations were imported into a reference database. Duplicates were removed and two reviewers assessed each identified publication separately. Results: Among a total of 204 references, 3 prospective randomized trials were identified. Two trials treated BV infections with PHMB in comparison to clindamycin as antibiotic standard therapy with no
\end{abstract}

significant differences either in safety or in efficacy. The third controlled trial investigated the clinical efficacy of PHMB compared to placebo in the treatment of human papilloma virus. Patients treated with PHMB daily for up to 16-weeks showed significantly higher (52\%) clearance of genital warts as compared to patients treated with placebo (4\%). Conclusion: $\mathrm{PHMB}$ may be a clinically effective alternative for the treatment of BV and human papilloma virus. Although PHMB-based antiseptics are available since the late 90 s, controlled trials to investigate its clinical potential for antiseptic treatment are scant. Clinical use of antiseptics for the treatment of infectious diseases should be explored and supported further.

Copyright $\odot 2012$ S. Karger AG, Basel

\section{Introduction}

The genital tract is an ecosystem for a multiplicity of microorganisms which have to be maintained in a fragile balance. If this balance is disturbed, infection may occur. Infectious diseases of the genital tract caused by bacteria, fungi, parasites, and viruses are a worldwide issue and are highly evidenced to impair somatic functions including

\section{KARGER}

Fax +41613061234 E-Mail karger@karger.ch www.karger.com
(ㄷ) 2012 S. Karger AG, Basel

$1660-5527 / 12 / 0256-0298 \$ 38.00 / 0$

Accessible online at:

www.karger.com/spp
Dr. rer. med. I. Koban

University Medicine Greifswald

Institute of Hygiene and Environmental Medicine

Walther Rathenau Strasse 49a, 17489 Greifswald (Germany)

Tel. +49383451 5530, E-Mail ina.koban@uni-greifswald.de 
reproduction $[1,2]$. Additionally, the vaginal flora may be a source for surgical site infections [3], urogenital tract infections during pregnancy [4], and newborn infections including an increased risk of preterm birth $[5,6]$.

Mycoplasma hominis is known to decrease fertility in males [7], whereas Mycoplasma genitalium and Chlamydia trachomatis are responsible for infertility in males and females $[8,9]$. Equally important are gonococcal infections which can cause urethritis, proctitis, cervicitis, and pelvic inflammatory disease with long-term effects such as infertility, ectopic pregnancy, and chronic pelvic pain [10]. Enterobacteriaceae like Escherichia coli or Enterococcus faecalis are the most common causes of nonsexually transmitted infections [2]. Pseudomonas aeruginosa as well as Gram-positive cocci that commonly colonize the male urethra can cause prostatitis and epididymitis and consecutively impair fertility [11]. Candida albicans was associated with male infertility because of an inhibitory effect on human sperms [12]. In the female genital tract, C. albicans is a common commensal but may also cause vaginitis and cervicitis [2]. Toxin-producing Staphylococcus aureus strains have been identified as underlying pathogens for the development of vaginal menstrual toxic shock syndrome [13-15]. Viral genital tract infections are mostly caused by herpes viruses, human papilloma viruses (HPV), and human immunodeficiency viruses (HIV) either due to the virus itself or to side effects.

Bacterial vaginosis (BV) is the most common disorder of the vaginal flora, caused by different microbial species, with a prevalence of $5-30 \%$ in adult females [16-18]. BV is associated with an increased risk of acute upper genital tract infection $[19,20]$. Vaginitis is the most common gynecologic diagnosis secondary to BV [21], vulvovaginal candidiasis [22], or trichomoniasis [23].

Infectious genital tract diseases are commonly treated with antibiotics such as clindamycin or metronidazole [24]. Today, antimicrobial chemotherapy is increasingly complicated by progressive antibiotic resistance [25]. Moreover, new insights into the structure and function of the colonization of the vagina help to explain why antibiotic treatment is only of limited use in infections involving microbial biofilms. The treatment of genital tract infections, in particular vaginosis and vaginitis, is therefore still a great challenge. Compared to oral antibiotic therapy, local treatment of genital tract infections shows less systemically side effects like nausea, vomiting, and taste perversion $[26,27]$.

Modern antiseptics are an excellent alternative to antibiotic treatment, provided that they combine a broad antimicrobial spectrum with low toxicity, high tissue compatibility, low or missing adsorption, and good applicability. Therefore, antiseptics are the first option for the treatment of local microbial infections.

In the past, chlorhexidine digluconate ( $\mathrm{CHX}$ ) was used as a general vaginal antiseptic for over three decades [28]. However, hyperkeratosis, ulceration, dysplasia, and a significant increase in DNA damages by $\mathrm{CHX}$ were observed in rat experiments [29, 30]. Additionally, concentration-dependent CHX significantly inhibits wound healing and granulation [31, 32], which corresponds with the cytotoxic effect on osteoblasts and odontoblast-like cells $[33,34]$. Moreover, degradation during storage may release the carcinogen 2-chloroanline from low-grade CHX [35].

Therefore, other antiseptics like PHMB [36] and octenidine [37] have moved into the focus of antiseptic treatment. While PHMB is a structural sibling of $\mathrm{CHX}$, it lacks many of its drawbacks because of the lack of 2-chloroanaline in the molecular structure of PHMB.

Polihexanide is well tolerated when used topically on skin, wounds [38], eyes [39, 40], and vaginal mucous membrane [41]. Only a negligible allergic risk, very low toxicity, and no adsorption of PHMB have been described [36]. Its tissue compatibility and biocompatibility is much better than that of CHX in vitro. Because of the additionally higher antimicrobial efficacy, PHMB achieved a better biocompatibility index than chlorhexidine and should be preferred [42]. Additionally, PHMB significantly stimulates wound healing [43] and there is no indication of any mutagenicity or carcinogenicity of PHMB in vitro or in vivo [38].

The efficacy of PHMB against infected wounds, prostheses, carcinomas, and methicillin-resistant $S$. aureus (MRSA) in vivo has been extensively studied in different controlled clinical studies. The antimicrobial activity of PHMB based on its exclusive interaction with acidic, negatively charged phospholipids in the bacterial membrane leads to increased fluidity, permeability, and loss of integrity, followed by the death of the organism [44-47]. Transferred to the cytoplasm it leads to disruption of the bacterial metabolism. Because neutral phospholipids are only slightly affected, PHMB has a low toxicity against human cells $[38,48,49]$. PHMB binds to cellular surfaces which is why it also has a sustained effect over hours $[39,50]$.

PHMB is commercially available in many formulations and for different indications including wound antisepsis, rinsing, and decolonization of unwanted organisms (e.g. MRSA) to name only a few. For genital treatment, $\mathrm{PHMB}$ is patented as a single-dose, isotonic topical 
Fig. 1. Flow diagram outlining the litera-

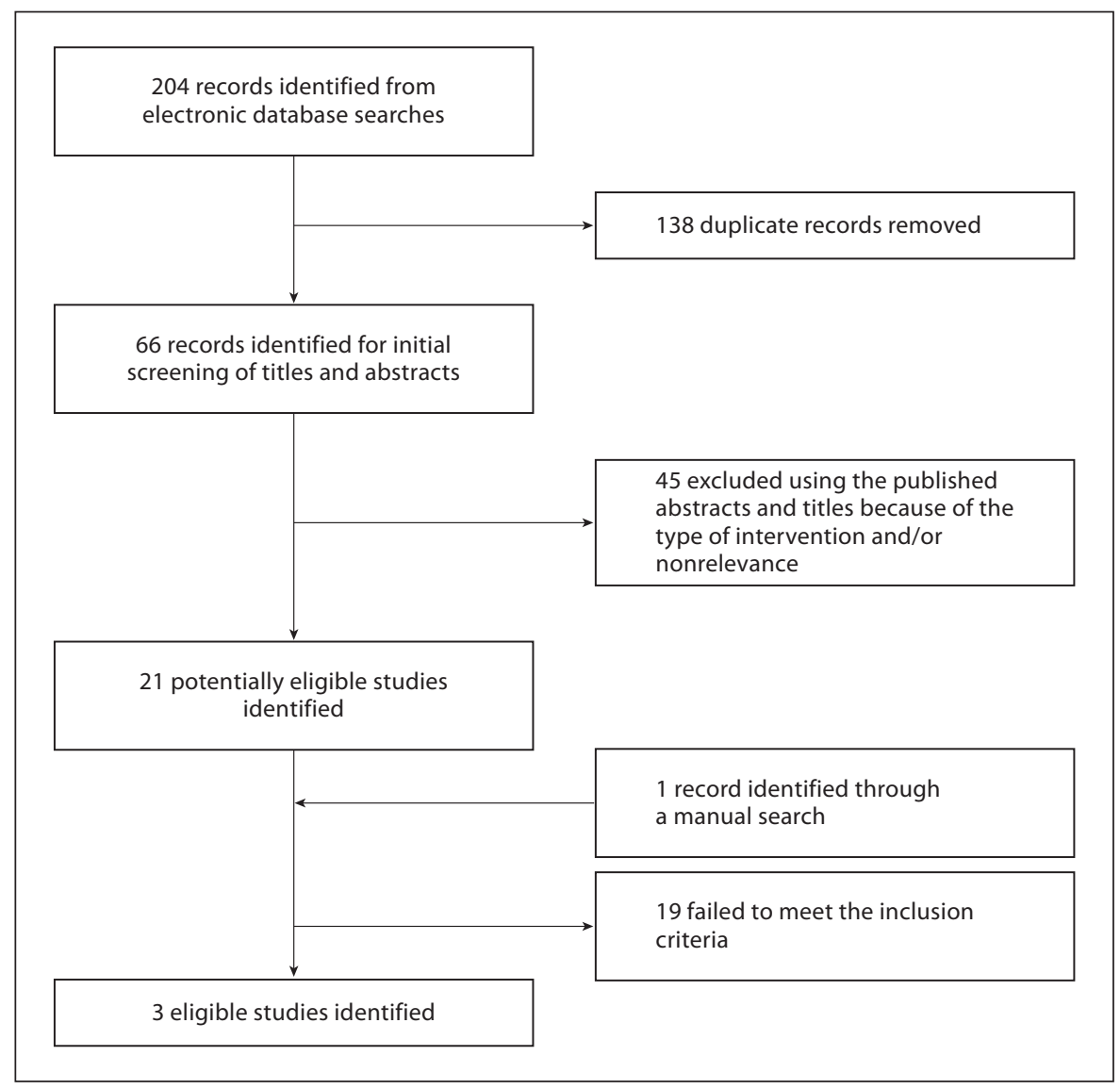
ture search and review of the studies.

solution (Monogin ${ }^{\circledR}$; Lo.Li. Pharma S.r.l., Rome, Italy). The purpose of this work is to review the existing literature on the antiseptic polihexanide (polyhexamethylene biguanide; $\mathrm{PHMB}$ ) for the treatment of genital tract infections.

\section{Methods}

A systematic search for manuscripts published in any language in the two electronic databases Pubmed and ISI Web of Science was performed. The following syntax for literature searches in both databases was used:

- Genital tract infection and PHMB or polihexanide or polyhexamethylene biguanide

- Vaginosis and PHMB or polihexanide or polyhexamethylene biguanide

- Vaginitis and PHMB or polihexanide or polyhexamethylene biguanide

No other limits were used. Bibliographies of manuscripts were screened for additional sources and an additional manual search was done.

Studies were included on the basis of four criteria: disease, therapy, study design, and outcome. The diseases of interest were genital tract infections, especially vaginosis and vaginitis. The therapy of interest was treatment with PHMB. Primarily, in vivo studies and clinical studies were selected. Additionally, in vitro studies were considered to emphasize the efficacy against the disease-causing pathogen. The outcome of interest was the comparison of PHMB treatment with a placebo or standard therapy.

All relevant titles, abstracts, and citations were imported into a reference database. Duplicates were removed and two reviewers independently assessed each publication separately. Differences in opinion were discussed among all authors and the final decision was made by means of open consensus. Both reviewers independently abstracted data from all selected studies.

\section{Results}

The search results are shown in a flow diagram (fig. 1). A total of 204 references were identified from the searches of the electronic databases. After omitting 138 duplicate references, 66 original references were further analyzed. Overall, 21 potentially eligible studies were identified. The search resulted in one further study. Nineteen references were excluded after review of the full text. The 
Table 1. Eligible studies

\begin{tabular}{|c|c|c|c|}
\hline $\begin{array}{l}\text { Study } \\
\text { (country) }\end{array}$ & Type & Setting & Outcome \\
\hline $\begin{array}{l}\text { Gerli }[41] \\
\text { (Italy) }\end{array}$ & $\begin{array}{l}\text { Prospective, randomized, } \\
\text { parallel-group study }\end{array}$ & $\begin{array}{l}\text { Among } 110 \mathrm{BV} \text { patients, the efficacy of a single-dose } \\
\text { PHMB vaginal gel versus a } 7 \text {-day clindamycin cream } \\
\text { treatment against BV was compared }\end{array}$ & $\begin{array}{l}\text { The efficacy of mono-dose } \\
\text { PHMB treatment was similar to } \\
\text { 7-days clindamycin cream } \\
\text { treatment }\end{array}$ \\
\hline $\begin{array}{l}\text { Marelli } \\
\text { et al. [63] } \\
\text { (Italy) }\end{array}$ & $\begin{array}{l}\text { Prospective, } \\
\text { double-blind, randomized, } \\
\text { placebo trial }\end{array}$ & $\begin{array}{l}\text { HPV patients ( } \mathrm{n}=140 \text { ), who applied PHMB daily for up } \\
\text { to } 16 \text { weeks, were cleared of warts in } 52 \% \text { of cases (warts } \\
\text { clearance in the placebo group, } 4 \% \text { ). In a } 12 \text {-week } \\
\text { treatment-free follow-up period, wart recurrence was } \\
\text { investigated. The recurrence rate after a } 12 \text {-week } \\
\text { treatment-free follow-up period was } 19 \% \text { in the PHMB } \\
\text { group and } 0 \% \text { in the placebo group }\end{array}$ & $\begin{array}{l}\text { PHMB is effective for the } \\
\text { treatment of genital papilloma } \\
\text { virus infections }\end{array}$ \\
\hline $\begin{array}{l}\text { Minozzi } \\
\text { et al. [57] } \\
\text { (Italy) }\end{array}$ & $\begin{array}{l}\text { Prospective, multicenter, } \\
\text { randomized, single-blind } \\
\text { and parallel-group study }\end{array}$ & $\begin{array}{l}\text { Among } 740 \text { BV patients, the efficacy of a single-dose } \\
\text { PHMB solution (Monogin) versus a 7-day clindamycin } \\
\text { cream treatment against BV was compared }\end{array}$ & $\begin{array}{l}\text { There were no significant } \\
\text { differences between the two } \\
\text { therapy regimes either in safety } \\
\text { or in efficacy }\end{array}$ \\
\hline
\end{tabular}

three remaining references were prospective randomized trials. In two trials, BV infections were treated with PHMB in comparison to clindamycin as standard therapy. The third trial investigated HPV patients treated with PHMB or a placebo in a randomized controlled study (table 1).

\section{In vitro Studies}

The broad antimicrobial efficacy of PHMB against microorganisms frequently causing genital tract infections has been repeatedly shown in vitro. PHMB was effective against planktonic E. coli and S. aureus as well as $P$. aeruginosa in suspension and biofilms [37-42, 51-53]. In addition, $\mathrm{PHMB}$ was also effective against $E$. faecalis and C. albicans [54], as well as against intracellular bacteria such as Chlamydia sp. and Neisseria sp. [52], and protozoa such as Acanthamoeba [53].

The virocidal in vitro efficacy of PHMB was investigated in two references. It was shown that $0.01 \%$ PHMB is effective against herpes viruses in vitro [58]. Krebs et al. [59] found a modest antiviral efficacy against cell-free and cell-associated HIV-1. Furthermore, they found that PHMB inhibited binding and entry of the virus.

\section{Clinical Studies}

Minozzi et al. [57] compared the efficacy of a singledose PHMB solution (Monogin) versus a 7-day clindamycin cream treatment against BV in a multi-center, randomized, single-blind and parallel-group study which en- rolled 740 patients. Twenty-one to 30 days after the start of the study, the authors found no significant $(95 \% \mathrm{CI}$, $\mathrm{p}=0.386$ ) differences between both therapy regimes either in safety or in efficacy. Safety was investigated by monitoring treatment-emergent adverse events (e.g. urinary tract infection) throughout the study. Namely, 30.4\% of all PHMB-treated patients and $26.8 \%$ of clindamycintreated patients had an adverse event, with no statistically significant difference. The efficacy was analyzed in a perprotocol group with 347 patients. Cure of BV in the perprotocol group was evaluated by frequencies of 'investigator cure' (requirement for additional therapy: $89.1 \%$ of the PHMB group, $86.4 \%$ of the clindamycin group achieved cure), 'clinical cure' (conservative symptomatic measure: $64.3 \%$ of the PHMB group, $63.2 \%$ of the clindamycin group achieved cure), 'Nugent cure' (diagnostic evaluation: $56.5 \%$ of the PHMB group, $57.7 \%$ of the clindamycin group achieved cure), and 'therapeutic cure' (symptomatic, interpretive, and diagnostic measures: $42.1 \%$ of the PHMB group, $45.6 \%$ of the clindamycin group achieved cure). Pertaining to the results, it seems that a single dose of PHMB is statistically equivalently effective to 7 daily doses of clindamycin for the treatment of BV.

Gerli and di Renzo [41] investigated patients treated with the same regimen (PHMB, $\mathrm{n}=59$; clindamycin, $\mathrm{n}=$ 51) and concluded that mono-dose PHMB treatment should be the therapy of choice for BV.

Marelli et al. [63] showed in a prospective, doubleblind, randomized placebo trial that PHMB is effective 
for the treatment of genital papilloma virus infections. Patients who applied PHMB daily for up to 16 weeks were significantly $(\mathrm{p}<0.0001)$ more frequently cleared of warts (52\%) as compared to patients in the placebo group (4\%). In a 12-week treatment-free follow-up period, wart recurrence was investigated. The recurrence rate after the 12 -week treatment-free follow-up period was $19 \%$ in the $\mathrm{PHMB}$ group and $0 \%$ in the placebo group.

\section{Discussion}

Genital tract infections are a serious challenge in gynecology as well as in urology. In the last decade it has become increasingly clear that antimicrobial chemotherapy is limited by an increasingly prevalent antibiotic resistance. Additionally, frequent and inappropriate use of antibiotics promotes resistance even further. With the availability of new antiseptic compounds with a broad antimicrobial spectrum, provided in easy-to-use and well-tolerated formulations, local treatment is expected to become more and more important in genital tract therapy of localized limited infections.

PHMB is a modern antiseptic that combines a broad antimicrobial spectrum with low toxicity and without long-term risks, and with high tissue compatibility, no reported adsorption, and good applicability as solution, gel, ointment, or foam [37]. The modes of action make the development of resistance to PHMB highly unlikely. Actually, no bacterial resistance has been described in vitro or from clinical or environmental samples [69]. The antimicrobial efficacy of PHMB is not impaired by protein and blood [71]. The most interesting feature of PHMB is its outstanding relation between antimicrobial efficacy and low cytotoxicity and exceptional tissue compatibility that has been repeatedly described by independent researchers in vitro, in animal models, and in controlled clinical studies and case reports. At low concentrations, PHMB even seems not only to be nontoxic but also to have a positive effect on the proliferation of human keratinocytes that promotes wound healing [60-62]. It is actually one of the most promising antiseptic substances and has been used in medicine for many indications for over 20 years.

Although the efficacy of PHMB against typical genital tract pathogens has been repeatedly demonstrated, the number of actual clinical studies published on the topic is limited because the introduction of PHMB in clinical practice (except in wound antisepsis) only started in the last decade. Identified studies show the clinical effective- ness of PHMB and go along well with results from in vivo studies and clinical data from other indications, e.g. wound infections and treatment of acanthamoeba keratitis [36]. Minozzi et al. [57] and Gerli et al. [41] compared the efficacy of a single-dose PHMB solution (Monogin) versus 7-day clindamycin cream treatment against BV and found no significant differences between the two therapy regimes in either safety or efficacy. The mechanism of action of clindamycin is based on the inhibition of protein synthesis by binding to the $50 \mathrm{~S}$ subunit of the bacterial ribosome, resulting in a mostly bacteriostatic effect. Therefore, the efficacy depends mainly on the period of time during which the effective concentration is above the minimum inhibitory concentration of the pathogen. Because both agents were self-administered by the patients, the efficacy depends also on the compliance, which is commonly better in cases of single treatment with PHMB.

Even the antiviral efficacy against genital papillomavirus could be demonstrated in a clinical trial [63]. In the past, CHX or antibiotics were often used for the treatment of genital tract infections. The evidence available today, though limited, indicates that even a single dose of PHMB is comparable to a 7-day antibiotic course but has no unwanted effects like induction of antimicrobial resistance.

Until now, a final evaluation of PHMB in comparison to other genital tract antiseptics, e.g. CHX, has not been possible because no studies comparing both substances are available. Due to the better tissue compatibility of PHMB compared with CHX, the in vitro effectiveness of $\mathrm{PHMB}$ in the presence of a bio-burden, the primary decreased susceptibility of enterococci strains against $\mathrm{CHX}$ [64], and the R-plasmid-coded CHX resistance in vitro [65-67] with possible cross-resistance against antibiotics [68], such studies would be highly appreciated as final evidence for the superiority of treatment of genital tract infections by PHMB as previously shown for other indications.

\section{Conclusion}

PHMB may be a clinically effective alternative for the treatment of BV and HPV. Although PHMB-based antiseptics have been available since the late 90 s, controlled trials to investigate its clinical potential for antiseptic treatment are scant. Clinical use of antiseptics for the treatment of infectious diseases should be explored and supported further. 


\section{Acknowledgment}

Funding for this research was provided by Lo.Li Pharma.

\section{Disclosure Statement}

The authors have no conflicts of interest that are directly relevant to the content of this study.

\section{References}

1 Larsen B: Vaginal flora in health and disease. Clin Obstetr Gynecol 1993;36:107-121.

-2 Pellati D, Mylonakis I, Bertoloni G, et al: Genital tract infections and infertility. Eur J Obstetr Gynecol Reprod Biol 2008;140:3-11.

-3 Larsson PG, Carlsson B: Does pre- and postoperative metronidazole treatment lower vaginal cuff infection rate after abdominal hysterectomy among women with bacterial vaginosis? Inf Dis Obstetr Gynecol 2002;10: 133-140.

4 Shopova E, Nikolov A, Dimitriv A: Link between the state of vaginal flora and the development of uroinfection during pregnancy (in Bulgarian). Akush Ginekol 2005;44:3839.

5 Tolosa JE: Chlorhexidine antisepsis to reduce neonatal mortality must be adopted globally. Ped Inf Dis J 2006;25:676-679.

-6 Lamont RF, Taylor-Robinson D: The role of bacterial vaginosis, aerobic vaginitis, abnormal vaginal flora and the risk of preterm birth. BJOG 2010;117:119-120.

7 Andrade-Rocha FT: Ureaplasma urealyticum and Mycoplasma hominis in men attending for routine semen analysis: prevalence, incidence by age and clinical settings, influence on sperm characteristics, relationship with the leukocyte count and clinical value. Urol Int 2003;71:377-381.

8 Cohen CR, Manhart LE, Bukusi EA, et al: Association between Mycoplasma genitali$u m$ and acute endometritis. Lancet 2002;359: 765-766.

-9 Svenstrup HF, Fedder J, Kristoffersen SE, et al: Mycoplasma genitalium, Chlamydia trachomatis, and tubal factor infertility - a prospective study. Fer Steril 2008;90:513-520.

10 Workowski KA, Berman SM, Douglas JM: Emerging antimicrobial resistance in Neisseria gonorrhoeae: urgent need to strengthen prevention strategies. Ann Intern Med 2008; 148:606-613.

11 Weidner W, Krause W, Ludwig M: Relevance of male accessory gland infection for subsequent fertility with special focus on prostatitis. Hum Reprod Update 1999;5:421-432.

-12 Tian YH, Xiong JW, Hu L, et al: Candida albicans and filtrates interfere with human spermatozoal motility and alter the ultrastructure of spermatozoa: an in vitro study. Int J Androl 2007;30:421-429.

13 Tang YW, Himmelfarb E, Willis M, Stratton CW: Characterization of three Staphylococcus aureus isolates from a 17-year-old female who died of tampon-related toxic shock syndrome. J Clin Microbiol 2010;48:1974-1977.
14 Ellies E, Vallée F, Mari A, Silva S, Bauriaud R, Fourcade O, Genestal M: Toxic shock syndrome consecutive to the presence of vaginal tampon for menstruation regressive after early haemodynamic optimization and activated protein C infusion. Ann Fr Anesth Reanim 2009;28:91-95.

15 Parsonnet J, Hansmann MA, Delaney ML, Modern PA, Dubois AM, Wieland-Alter W Wissemann KW, Wild JE, Jones MB, Seymour JL, Onderdonk AB: Prevalence of toxic shock syndrome toxin 1-producing Staphylococcus aureus and the presence of antibodies to this superantigen in menstruating women. J Clin Microbiol 2005;43:46284634.

16 Eschenbach DA, Hillier S, Critchlow C, et al: Diagnosis and clinical manifestations of bacterial vaginosis. Am J Obstetr Gynecol 1988;158:879-828.

17 Hillier S, Holmes KK: Bacterial Vaginosis. New York, McGraw-Hill, 1999.

18 Hoyme UB, Eschenbach DA: Bakterielle Vaginose. Dtsch Med Wochenschr 1985;110: 349-352.

19 Harmanli OH, Cheng GY, Nyirjesy P, et al: Urinary tract infections in women with bacterial vaginosis. Obstetr Gynecol 2000;95: $710-712$.

20 Hillebrand L, Harmanli OH, Whiteman V, et al: Urinary tract infections in pregnant women with bacterial vaginosis. Am J Obstetr Gynecol 2002;186:916-917.

21 Sobel JD: Bacterial vaginosis. Annu Rev Med 2000;51:349-356.

22 Spinillo A, Capuzzo E, Gulminetti R, et al: Prevalence of and risk factors for fungal vaginitis caused by non-albicans species. Am J Obstet Gynecol 1997;176:138-141.

23 Wølner-Hanssen P, Krieger JN, Stevens CE et al: Clinical manifestations of vaginal trichomoniasis. JAMA 1989;261:571-576.

24 Joesoef MR, Schmid GP, Hillier SL: Bacterial vaginosis: review of treatment options and potential clinical indications for therapy. Clin Infect Dis 1999;28(suppl 1):S57-S65.

25 Colsky AS, Kirsner RS, Kerdel FA: Analysis of antibiotic susceptibilities of skin wound flora in hospitalized dermatology patients: the crisis of antibiotic resistance has come to the surface. Arch Dermatol 1998;134:10061009.

26 Fischbach F, Petersen EE, Weissenbacher ER, et al: Efficacy of clindamycin vaginal cream versus oral metronidazole in the treatment of bacterial vaginosis. Obstetr $\mathrm{Gy}$ necol 1993;82:405-410.
27 Paavonen J, Mangioni C, Martin MA, et al: Vaginal clindamycin and oral metronidazole for bacterial vaginosis: a randomized trial. Obstetr Gynecol 2000;96:256-260.

-28 Shubair M, Stanek R, White S, et al: Effects of chlorhexidine gluconate douche on normal vaginal flora. Gynecol Obstet Invest 1992;34:229-233.

29 Grassi TF, Camargo EA, Salvadori DMF, et al: DNA damage in multiple organs after exposure to chlorhexidine in Wistar rats. Int J Hyg Environ Health 2007;210:163-167.

- 30 Sonis ST, Clark WB, Shklar G: Chlorhexidine-induced lingual keratosis and dysplasia in rats. J Periodontol 1978;49:585-591.

-31 Bassetti C, Kallenberger A: Influence of chlorhexidine rinsing on the healing of oral mucosa and osseous lesions. J Clin Periodontol 1980;7:443-456.

-32 Paunio KU, Knuttila M, Mielitynen H: The effect of chlorhexidine gluconate on the formation of experimental granulation tisue. J Periodontol 1978;49:92-95.

-33 Lee TH, Hu CC, Lee SS, et al: Cytotoxicity of chlorhexidine on human osteoblastic cells is related to intracellular glutathione levels. Int Endod J 2010;43:430-435

34 Lessa FC, Aranha AM, Nogueira I, et al: Toxicity of chlorhexidine on odontoblast-like cells. J Appl Oral Sci 2010;18:50-58.

35 Gavlick WK, Davis PK: Gas chromatographic determination of p-chloroaniline in a chlorhexidine digluconate-containing alcohol foam surgical scrub product. J AOAC Int 1994;77:583-586.

36 Hübner NO, Kramer A: Review on the efficacy, safety and clinical applications of polihexanide, a modern wound antiseptic. Skin Pharmacol Physiol 2010;23:17-27.

37 Hübner NO, Siebert J, Kramer A: Octenidine dihydrochloride, a modern antiseptic for skin, mucous membranes and wounds. Skin Pharmacol Physiol 2010;23:244-258.

38 Kramer A, Roth B: Polihexanid; in Kramer A, Assadian O (eds): Wallhäussers Praxis der Sterilisation, Desinfektion, Antiseptik und Konservierung. Stuttgart, Thieme, 2008, pp 789-793.

39 Hansmann F, Kramer A, Ohgke H, et al: Polyhexamethylbiguanid (PHMB) as preoperative antiseptic for cataract surgery. Ophthalmologe 2004;101:377-383. 
-40 Hansmann F, Kramer A, Ohgke H, et al: Lavasept as an alternative to PVP-iodine as a preoperative antiseptic in ophthalmic surgery: randomized, controlled, prospective double-blind trial. Ophthalmologe 2005; 102:1043-1046.

-41 Gerli SDR, Di Renzo GC: A new approach for the treatment of bacterial vaginosis: use of polyhexamethylene biguanide - a prospective, randomized study. Eur Rev Med Pharmacol Sci 2003;7:127-130.

-42 Müller G, Kramer A: Biocompatibility index of antiseptic agents by parallel assessment of antimicrobial activity and cellular cytotoxicity. J Antimicrob Chemother 2008;61: 1281-1287.

43 Kramer A, Daeschlein G, Kammerlander G, et al: Konsensusempfehlung zur Auswahl von Wirkstoffen für die Wundantiseptik. Hyg Med 2004;29:147-157.

44 Gabriel GJ, Som A, Madkour AE, Eren T, Tew GN: Infectious disease: connecting innate immunity to biocidal polymers. Mater Sci Eng R Rep 2007;57:28-64.

$\checkmark 45$ Gilbert P, Moore LE: Cationic antiseptics: diversity of action under a common epithet. J Appl Microbiol 2005;99:703-715.

46 Ikeda T, Ledwith A, Bamford CH, et al: Interaction of a polymeric biguanide biocide with phospholipid membranes. Biochim Biophys Acta 1984;769:57-66.

47 Yasuda K, Ohmizo C, Katsu T: Potassium and tetraphenylphosphonium ion-selective electrodes for monitoring changes in the permeability of bacterial outer and cytoplasmic membranes. J Microbiol Methods 2003; 54:111-115.

48 Ikeda T, Tazuke S, Watanabe M: Interaction of biologically active molecules with phospholipid membranes. 1. Fluorescence depolarization studies on the effect of polymeric biocide bearing biguanide groups in the main chain. Biochim Biophys Acta 1983;735: 380-386.

49 Ikeda T, Tazuke S, Bamford C, et al: Spectroscopic studies on the interaction of polymeric in-chain biguanide biocide with phospholipid membranes as probed by 8 -anilinonaphthalene-1-sulfonate. Bull Chem Soc Jpn 1985;58:705-709.
50 Rosin M, Welk A, Kocher T, et al: The effect of a polyhexamethylene biguanide mouthrinse compared to an essential oil rinse and a chlorhexidine rinse on bacterial counts and 4-day plaque regrowth. J Clin Periodonto 2002;29:392-399.

51 Gilbert P, Das JR, Jones MV, et al: Assessment of resistance towards biocides following the attachment of micro-organisms to, and growth on, surfaces. J Appl Microbio 2001;91:248-254.

52 Hammann A, Huebner NO, Bender C, et al: Antiseptic efficacy and tolerance of tissuetolerable plasma compared with two wound antiseptics on artificially bacterially contaminated eyes from commercially slaughtered pigs. Skin Pharmacol Physiol 2010;23. 328-332.

53 Müller G, Kramer A: Effect of selected, wound antiseptics on adult articular cartilage (bovine sesamoid bone) in the presence of Escherichia coli and Staphylococcus aureus. J Orthop Res 2005;23:127-133.

54 Koburger T, Hübner NO, Braun M, et al: Standardized comparison of antiseptic efficacy of triclosan, PVP-iodine, octenidine dihydrochloride, polyhexanide and chlorhexidine digluconate. J Antimicrob Chemother 2010;65:1712-1719.

55 Minozzi M, Gerli S, Di Renzo GC, et al: The efficacy and safety of a single dose of polyhexamethylene biguanide gynaecologic solution versus a seven-dose regimen of vaginal clindamycin cream in patients with bacterial vaginosis. Eur Rev Med Pharmacol Sci 2008;12:59-65.

56 Valluri S, Fleming TP, Laycock KA, et al: In vitro and in vivo effects of polyhexamethylene biguanide against herpes simplex virus infection. Cornea 1997; 16:556-559.

57 Krebs FC, Miller SR, Ferguson ML, et al: Polybiguanides, particularly polyethylene hexamethylene biguanide, have activity against human immunodeficiency virus type 1. Biomed Pharmacother 2005;59:438445.
58 Fiscella RG, Moshifar M, Messick CR, et al: Polyhexamethylene biguanide (PHMB) in the treatment of experimental Fusarium keratomycosis. Cornea 1997;16:447-449.

59 Roth B, Baltzer K: Preliminary treatment of the recipient site and healing of open spongiosa transplant in post-traumatic osteitis. Helv Chir Acta 1989;56:571-572.

60 Roth B, Baltzer K: Preventive intraoperative irrigation in wound management with Lavasept: report of experiences with 1,610 cases. Z Unfallchir Versicherungsmed 1990;83: 224-226.

61 Marelli G, Papaleo E, Origoni M, et al: Polyhexamethylene biguanide for treatment of external genital warts: a prospective, doubleblind, randomized study. Eur Rev Med Pharmacol Sci 2005;9:369-372.

62 Kampf G, Hofer M, Wendt C: Efficacy of hand disinfectants against vancomycin-resistant enterococci in vitro. J Hosp Infect 1999;42:143-150.

63 Russell AD: Plasmids and bacterial resistance to biocides. J Appl Microbiol 1997;83: 155-165.

64 Tattawasart U, Maillard JY, F, et al: Development of resistance to chlorhexidine diacetate and cetylpyridinium chloride in Pseudomonas stutzeri and changes in antibiotic susceptibility. J Hosp Infect 1999;42:219-229.

65 Yamamoto T, Tamura Y, Yokota T: Antiseptic and antibiotic resistance plasmid in Staphylococcus aureus that possesses ability to confer chlorhexidine and acrinol resistance. Antimicrob Agents Chemother 1988; 32:932-935

66 Lambert RJ, Joynson J, Forbes B: The relationships and susceptibilities of some industrial, laboratory and clinical isolates of Pseudomonas aeruginosa to some antibiotics and biocides. J Appl Microbiol 2001;91:972-984.

67 Moore LE, Ledder RG, Gilbert P, et al: In vitro study of the effect of cationic biocides on bacterial population dynamics and susceptibility. Appl Environ Microbiol 2008;74: 4825-4834.

68 Koburger T, Müller G, Eisenbeiss W, et al: Microbicidal activity of polihexanide. GMS Krankenhaushyg Interdiszip 2007;2:Doc44. 